\title{
Sensing electrochemical activity in polymer coated metals during the early stages of coating degradation - Effect of the polarization of the substrate
}

\author{
R.M. Souto ${ }^{a}$, J.J. Santana ${ }^{b}$, L. Fernández-Méridaa ${ }^{a}$ S. González ${ }^{a}$ \\ a Department of Physical Chemistry, University of La Laguna, Faculty of Chemistry, E- \\ 38200 La Laguna (Tenerife), Spain \\ ${ }^{\mathrm{b}}$ Department of Process Engineering, University of Las Palmas de Gran Canaria, Campus \\ Universitario de Tafira, E-35017 Las Palmas de Gran Canaria, Spain
}

\begin{abstract}
Eventual limitations in the applicability of the SECM in the SG-TC mode to in situ monitor electrochemical activity in the proximity of a subcentimeter defect (holiday) through the coating applied to protect a metal against the corrosive environments has been explored. The possible occurrence of chemical interferences between the chemical species involved in the corrosion reactions, as well as the formation of reactive secondary products, have been investigated because they would influence the faradaic signals registered at the SECM tip. In order to separate the contributions of the half-cell processes, polarization of the substrate was performed in this work, both negative and positive with respect to the spontaneously-developed open circuit potential of the sample in the test environment, and the signals detected at the tip were analyzed. By selecting different values for the potential applied to the tip, the local concentrations of $\mathrm{Fe}$ (II) ions, hydrogen peroxide and oxygen could be monitored. It has been observed that the oxygen reduction reaction occurring at the cathodic sites on the corroding steel surface can be accompanied by the formation of hydrogen peroxide as intermediate, and this species will interfere with the detection of dissolved metal at the tip.
\end{abstract}

Keywords: Scanning electrochemical microscopy; organic coating; degradation; iron dissolution; oxygen reduction. 


\section{Introduction}

Scanning microelectrochemical techniques, which are an extension of local probe techniques originating from the use of microelectrodes as the probes in near field microscopic techniques to operate inside an electrochemical cell, are finding increasing use in the corrosion laboratory for the investigation of a wide variety of reactions. Their applicability arises from the need of information on the spatial distribution of the species consumed or released on the active sites to understand many corrosion reactions, whereas conventional electrochemical methods can only provide information about the overall activity on the entire surface. Thus, in-situ sensing of the processes in active sites, pores or defects can be achieved only by using localized techniques such as scanning electrochemical microscopy (SECM) [1,2], scanning vibrating electrode technique (SVET) [3], scanning ion-selective electrode technique (SIET) [4], and localized electrochemical impedance spectroscopy (LEIS) [3]. Among them, scanning electrochemical microscopy operating in the negative-feedback mode has been successfully employed to obtain spatially-resolved information regarding surface topology, water uptake and blister formation at intact coatings [5-7]. Topographical lines and maps as well as chronoamperometric plots can be measured through the addition of a reversible redox mediator to the electrolytic phase. In this way, the specific effect of chloride ions towards blister formation under the coating could be monitored at a much earlier stage [8-13].

An even greater applicability has been found for SECM operating in the generation-collection (SG-TC) mode to follow the onset and progress of corrosion reactions within coating defects. The substrate under investigation is kept unbiased, i.e., effectively operating at its spontaneouslydeveloped open circuit potential in the immersed electrolyte. The progress of the corrosion reaction is related to the localized distribution of anodic and cathodic regions on the exposed metal within the defect. By adequately selecting the potential applied to the ultramicroelectrode tip, both the release of metal ions at the anodic sites and the consumption of oxygen at the cathodic sites developed in holidays could be monitored [14-16]. Since then, several other laboratories have adopted similar experimental procedures for the investigation of a variety of metal/coating systems [17-21], covering diverse metal substrates $[17,18]$, as well as a variety of paint formulations $[19,20]$, including systems with self-healing characteristics that could be monitored at significantly shorter exposures and greater sensitivities than by using conventional electrochemical techniques [21].

Despite the customary use of SECM in the SG-TC mode to characterize defective coatings, the possible occurrence of chemical interferences between the chemical species involved in both corrosion half reactions as well as the formation of reactive secondary products has not been explored, though they may have a significant influence on the faradaic signals registered on the SECM tip. This situation is especially relevant in relation to the oxygen reduction reaction occurring at the cathodic sites on the corroding sample, which is not a reversible reaction, and it is usually 
accompanied by the formation of hydrogen peroxide as intermediate. Thus, specific studies on the electrochemical activity of defective coated metals and the reactions involved by using scanning electrochemical microscopy are needed. In order to separate the contributions of the corrosion halfcell reactions, polarization of the substrate was performed in this work, both negative and positive with respect to the spontaneously-developed open circuit potential of the sample in the test environment, and the signals detected at the SECM tip were analyzed. The implications of these experiments are particularly relevant towards the use of the SG-TC operation mode of SECM to characterize the degradation reactions and anticorrosion performance of metal-coating systems, particularly during the early stages of coating degradation.

\section{Experimental}

\subsection{Materials and electrode preparation}

A polyurethane coating (Sigma Semigloss from Sigma Coatings, Amsterdam, The Netherlands) was employed. Mild steel plates were employed in this work. After cleaning and degreasing with acetone, mild steel plates were pretreated by grinding with 600- and 1200-grit SiC sandpaper, followed by degreasing with acetone. The coating was applied using a drawn down bar, and the coupons were allowed to cure for a week at room temperature and humidity. The dry film thickness of the resulting coating was $67 \pm 10 \mu \mathrm{m}$ as measured using a Mega-Check FN coating thickness-meter (List-Magnetik $\mathrm{GmbH}$, Germany). Samples of dimensions $2 \mathrm{~cm} \times 2 \mathrm{~cm}$ were cut from the coated plates, and artificial circular defects in the organic coating of ca. $170 \mu \mathrm{m}$ diameter were produced using a driller. The samples were then exposed to naturally-aerated $0.1 \mathrm{M} \mathrm{KCl}$ aqueous solution at room temperature $\left(20^{\circ} \mathrm{C}\right)$, and examined using SECM at regular intervals. The test electrolyte was prepared using analytical grade chemicals.

\subsection{Scanning electrochemical microscopy and experimental procedure}

The scanning electrochemical microscopy mode employed was sample generation-tip collection (SG-TC). Instrumentation and experimental arrangements have been described in detail previously [14-16]. Briefly, scans conducted both vertically (approach curves) and parallel to the sample surface were collected with a SECM instrument from $\mathrm{CH}$ Instruments (CH900, Austin, TX, USA) placed inside an active isolation workstation. Pt microelectrodes of $10 \mu \mathrm{m}$ dia. were employed as the probe, an $\mathrm{Ag} / \mathrm{AgCl} / \mathrm{KCl}$ (sat.) reference electrode and a Pt wire counter electrode, all set up in 
a cell made of polytetrafluoroethene. All potential values given below are referred to the $\mathrm{Ag} / \mathrm{AgCl} / \mathrm{KCl}$ (sat.) reference electrode. Specimens were mounted horizontally facing upwards.

The operating distance of the microelectrode tip over the coated surface was established by measuring the corresponding approach curves at a location sufficiently far from the holiday on nonbiased samples. The tip potential was set at $-0.70 \mathrm{~V}(\mathrm{Ag} / \mathrm{AgCl} / \mathrm{KCl}(\mathrm{sat}$.)) employing oxygen reduction as the electrochemical mediator reaction at the UME. After the experimental curves were fitted to the theoretical model for negative-feedback behaviour, and the exact tip-distance could thus be determined, the tip was retracted from the surface to a height of $10 \mu \mathrm{m}$ which was set as the tipsubstrate distance for the experiments measured parallel to the surface. Polarization was then applied to the substrates for $30 \mathrm{~s}$ prior to recording scans parallel to the sample surface passing over the holiday, and subsequently left unbiased until a stable open circuit potential could be measured again, and the measurement process could be repeated.

\section{Results and discussion}

\subsection{Substrate under cathodic polarization}

The cathodic half-cell reaction was first explored. In this case, by biasing the substrate negative to its open circuit potential, the reduction of oxygen can occur at the uncoated metal inside the holiday, according to equation (1):

$$
\mathrm{O}_{2}+2 \mathrm{H}_{2} \mathrm{O}+4 \mathrm{e}^{-} \leftrightarrow 4 \mathrm{OH}^{-}
$$

which corresponds to the oxygen reduction through an overall four electron reduction process to produce hydroxide ions. Resulting from the cathodic reaction, depletion of oxygen content in the electrolyte must be observed when the tip is scanned over the defect in the coating. Indeed, this is the result depicted in Figure 1A, which corresponds to a scan line measured by setting the tip potential at $-0.70 \mathrm{~V}(\mathrm{Ag} / \mathrm{AgCl} / \mathrm{KCl}($ sat.) $)$ whereas the substrate was polarized at $-1.00 \mathrm{~V}$ $(\mathrm{Ag} / \mathrm{AgCl} / \mathrm{KCl}($ sat.)), i.e., approximately $0.50 \mathrm{~V}$ negative to its corresponding open circuit potential of the defective sample in the electrolyte. In this way, the advancement of the cathodic reaction can be effectively monitored from the oxygen consumption occurring at the corroding metal, and the tip measures smaller faradaic currents for oxygen electroreduction when passing over the holiday, despite the greater electrolyte volume in the holiday [17]. Since the anodic half-cell corrosion reaction is suppressed by the high negative overpotential applied to the substrate, no faradaic currents should be observed if the tip potential is set at more positive potentials for recording electrooxidation currents instead. This is the typical procedure employed to characterize the anodic half-cell corrosion reactions when substrates are left unbiased [14-21]. Unfortunately, the scan lines 
given in figures $1 \mathrm{~B}$ and $1 \mathrm{C}$ show that this is not the case because the polarization period of 30 seconds was not long enough for the electrolytic volume inside the holiday to be washed away of the species formed whereas the sample was left at its open circuit potential. That is, corrosion reactions already occurred on the defective sample whereas the tip-sample distance was established for the SECM operation. Thus, electrooxidation currents are effectively detected at the SECM tip, and they are observed in the potential range $+0.07 \leq E_{t i p} \leq+0.60 \mathrm{~V}(\mathrm{Ag} / \mathrm{AgCl} / \mathrm{KCl}(\mathrm{sat})$.$) .$ That is, electrooxidation currents are measured even at potential values well below the onset of iron(II) oxidation reaction [22]:

$$
\mathrm{Fe}^{2+} \rightarrow \mathrm{Fe}^{3+}+1 \mathrm{e}^{-} \quad E^{0}=+0.55 \vee \text { vs } \mathrm{Ag} / \mathrm{AgCl} / \mathrm{KCl}(\text { sat. })
$$

(cf. figure 1B recorded with $E_{t i p}=+0.07 \mathrm{~V}(\mathrm{Ag} / \mathrm{AgCl} / \mathrm{KCl}($ sat. $\left.))\right)$. Therefore, the formation of hydrogen peroxide as byproduct cannot be neglected in this work, though the magnitude of the peak currents measured for $\mathrm{H}_{2} \mathrm{O}_{2}$ oxidation are at least 50 times smaller than the current associated to oxygen reduction in Figure 1A. (A word of caution must be provided at this stage, because the signal recorded in figure $1 \mathrm{~A}$ effectively corresponds to a much greater oxygen consumption compared to the background signal measured outside the holiday. That is, the holiday in the coating also provides a non-confined electrolyte volume due to the bigger dimensions of the holiday compared to those of the SECM tip -see ref. [17] for further details-, resulting in no hindrance to the diffusion of oxygen species from the bulk electrolyte). Additional support for the formation of $\mathrm{H}_{2} \mathrm{O}_{2}$ in the cathodic reaction at the substrate is given by Figure 2 depicting a cyclic voltammogram recorded at the SECM tip placed over the center of the holiday whereas the substrate was polarized at $-1.00 \mathrm{~V}$ $(\mathrm{Ag} / \mathrm{AgCl} / \mathrm{KCl}($ sat.)$)$. It is observed that oxidation currents occur at potential values more positive than $-0.12 \mathrm{~V}(\mathrm{Ag} / \mathrm{AgCl} / \mathrm{KCl}($ sat.)) during the positive-going scan. In this case, the redox process monitored at the UME could correspond to the oxidation of hydrogen peroxide given by the equation $[23,24]:$

$\mathrm{H}_{2} \mathrm{O}_{2}+2 \mathrm{OH}^{-} \rightarrow 2 \mathrm{e}^{-}+\mathrm{O}_{2}+2 \mathrm{H}_{2} \mathrm{O} \quad E^{0}=-0.33$ V vs. Ag/AgCl/KCl(sat.)

\subsection{Substrate under anodic polarization}

A similar sequence of experiments was also performed by polarizing the sample $0.30 \mathrm{~V}$ positive to its corresponding open circuit potential in the electrolyte to investigate the processes associated with the anodic half-cell reaction. Figure 3 displays the line scans obtained in this case when the tip potential was set in the region of oxygen reduction (Figure $3 \mathrm{~A}$ ), in the range of soluble 
$\mathrm{Fe}$ (II) species the oxidation (Figure 3C), and at an intermediate value between them (Figure 3B). The release of soluble metal species from the corroding metal inside the holiday is clearly observed as the tip is passed over the defect from the inspection of Figure 3C. That is, anodic polarization of the sample with respect to the open circuit potential promotes the corrosion of the exposed metal at the bottom of the holiday with the dissolution of Fe(II) species. The extent of this process completely masks the detection of iron species originating from the previous exposure of the sample to the electrolyte under open circuit conditions despite the rather short polarization time (i.e. $30 \mathrm{~s}$ ) given to the sample before recording the scan lines. This observation is more evident when observing the plot given in Figure 1C measured during cathodic polarization of the sample. In the later, a measurable signal for $\mathrm{Fe}(\mathrm{II})$ and hydrogen peroxide oxidation could be measured when the tip scanned outside the holiday, though a higher signal was yet obtained when the tip passed above the holiday. This was due to both the formation of hydrogen peroxide as byproduct of oxygen reduction and the confined electrolyte volume inside the defect. This conclusion is further supported by inspecting the scan line depicted in Figure 3B that was obtained with the tip potential set at +0.25 $\mathrm{V}(\mathrm{Ag} / \mathrm{AgCl} / \mathrm{KCl}$ (sat.)) whereas the sample was anodically polarized. In this case, the potential applied to the UME is too negative for metal ions to be oxidized and the faradaic current measured originates from the oxidation of hydrogen peroxide species exclusively. The higher currents are now observed when the tip is scanned outside the holiday and decreases abruptly to zero when the holiday contour is passed. A non-zero signal is still detected over the centre of the holiday, which results from the volume of electrolyte inside the holiday which has not been completely washed away and contained some residual hydrogen peroxide from the previous condition of the sample left at open circuit. This feature is also found in Figure 3A for the electroreduction of oxygen because an electrolyte partially depleted in oxygen is found when the tip passed above the holiday. That is, the $30 \mathrm{~s}$ polarization period is too short for the complete renewal of the electrolyte inside the holiday to be completed, thus allowing us to observe the effects of both polarization and open circuit potential preconditioning of the sample to be explored in the same experiment.

In order to confirm the observations raised above, the sample was subsequently subjected to a sequence of operations involving changes in its electrical state; namely the sample was first left unpolarized and subsequently polarized again at $-0.15 \mathrm{~V}(\mathrm{Ag} / \mathrm{AgCl} / \mathrm{KCl}($ sat.) $)$ whereas scan lines were registered at the tip for the same potential conditions of the previous experiment for the two conditions applied to the sample. The curves plotted in Figure 4 demonstrate that hydrogen peroxide is formed during the consumption of soluble oxygen in the defect (cf. full lines in Figures $4 \mathrm{~A}$ and $4 \mathrm{~B}$ ). Immediate polarization of the sample shows that renewal of the electrolyte inside the holiday is only produced by the convective effect due to the movement of the tip as it moves from the left to the right. That is, a significant increase of the amount of oxygen detected at the tip in Figure 4A is observed as the border of the holiday is passed due to the greater volume of electrolyte available for diffusion to the tip [6,16], but this effect is quickly compensated by the depleted oxygen 
content of the confined electrolyte. The schematics in Figure 5 describes how the tip will encounter an enriched oxygen content as it passes over the holiday if no redox reaction involving this species occurs inside the holiday (cf. Figure 5A), whereas this effect can be counteracted if oxygen is electroreduced at the exposed metal in the defect, thus effectively resulting in smaller currents measured at the tip due to the depleted oxygen content in the electrolyte (see Figure 5B).

The response observed when the tip potential of $0.25 \mathrm{~V}(\mathrm{Ag} / \mathrm{AgCl} / \mathrm{KCl}($ sat.)) was applied (see Figure $4 \mathrm{~B}$ ) is also consistent with the given description. A signal related to the formation of a species is found when the sample is left unpolarized (full line), and this signal is also found when the sample is anodically polarized except as the tip enters the holiday because of convective refreshment of the electrolyte by the probe. Finally, inspection of Figure $4 \mathrm{C}$ shows that the release of iron soluble species was stopped whereas the sample was left unpolarized (the tip currents closely match those monitored for $E_{t i p}=+0.25 \mathrm{~V}(\mathrm{Ag} / \mathrm{AgCl} / \mathrm{KCl}($ sat. $))$. And net release of $\mathrm{Fe}(\mathrm{II})$ soluble species occurred again after the anodic polarization of the sample was restored.

\section{Conclusions}

It has been confirmed that SECM in the SG-TC mode can be employed to investigate the onset and progress of corrosion reactions within coating defects. Changes in $\mathrm{Fe}(\mathrm{II}), \mathrm{H}_{2} \mathrm{O}_{2}$ and $\mathrm{O}_{2}$ contents in the electrolyte next to the holiday can be effectively monitored by adequate selection of the tip potential. The cathodic corrosion process can thus be followed through the consumption of soluble oxygen due to its electroreduction, whereas the anodic reaction can be followed by oxidizing the released $\mathrm{Fe}$ (II) species. The possible interference of hydrogen peroxide on the later must be accounted for, because they are also oxidized at the positive potential values employed for the oxidation of the metal ions, though its contribution can be subtracted from the total current measured at the tip by recording scan lines at tip potentials below the onset of Fe(II) oxidation.

The release of iron soluble species is facilitated when the sample is polarized at potential values positive to the open circuit potential of the defective sample in the test electrolyte. Higher tip currents are thus measured at a given location above the sample that for the unpolarized sample because the corrosion rate of the system is not longer limited by the cathodic discharge of oxygen.

The formation of hydrogen peroxide is a byproduct of oxygen reduction at the steel surface, which can be observed under both open circuit and cathodic polarization conditions.

\section{Acknowledgements:}


This work was supported by the Ministerio de Ciencia y Tecnología (Madrid, Spain) and the European Regional Development Fund (Brussels, Belgium) under Project No. CTQ2009-14322. A grant awarded to JJS by the Gobierno de Canarias (Spain) to conduct a research stay at the University of La Laguna is gratefully acknowledged. Thanks are due to Sigma Coatings (Amsterdam, The Netherlands) for providing the coatings.

\section{References}

1. S.E. Pust, W. Maier, G. Wittstock, Investigation of localized catalytic and electrocatalytic processes and corrosion reactions with scanning electrochemical microscopy (SECM), Z. Phys. Chem. 222 (2008) 1463-1517.

2. L. Niu, Y. Yin, W. Guo, M. Lu, R. Qin, S. Chen, Application of scanning electrochemical microscope in the study of corrosion of metals, J. Mater. Sci. 44 (2009) 4511-4521.

3. R.S. Lillard, Scanning electrode techniques for investigating near-surface solution current densities, in: P. Marcus, F. Mansfeld (Eds.), Analytical Methods in Corrosion Science and Engineering; CRC Press, Boca Raton (FL) 2006, pp.571-601.

4. S. Lamaka, R.M. Souto, M.G.S. Ferreira, In situ visualization of local corrosion by scanning ionselective electrode technique (SIET), in: A. Méndez-Vilas, J. Díaz (Eds.), Microscopy: Science, technology, applications and education, Vol. 4; Formatex Research Center, Badajoz (Spain), 2010, in press.

5. A.C. Bastos, A.M. Simões, S. González, Y. González-García, R.M. Souto, Application of the scanning electrochemical microscope to the examination of organic coatings on metallic substrates, Prog. Org. Coat. 53 (2005) 177-182.

6. Y. González-García, J.J. Santana, J. González-Guzmán, J. Izquierdo, S. González, R.M. Souto, Scanning electrochemical microscopy for the investigation of localized degradation processes in coated metals. Prog. Org. Coat. 69 (2010) 110-117.

7. R.M. Souto, S. Lamaka, S. González, Uses of scanning electrochemical microscopy in corrosion research, in: A. Méndez-Vilas, J. Díaz (Eds.), Microscopy: Science, technology, applications and education, Vol. 4; Formatex Research Center, Badajoz (Spain), 2010, in press.

8. R.M. Souto, Y. González-García, S. González, G.T. Burstein, Damage to paint coatings caused by electrolyte immersion as observed in situ by scanning electrochemical microscopy, Corros. Sci. 46 (2004) 2621-2628.

9. R.M. Souto, Y. González-García, S. González, Evaluation of the corrosion performance of coilcoated steel sheet as studied by scanning electrochemical microscopy, Corros. Sci. 50 (2008) 1637-1643. 
10. R.M. Souto, Y. González-García, S. González, Characterization of coating systems by scanning electrochemical microscopy: surface topology and blistering, Prog. Org. Coat. 65 (2009) 435439.

11. R.M. Souto, Y. González-García, S. González, G.T. Burstein, Imaging the origins of coating degradation and blistering caused by electrolyte immersion assisted by SECM, Electroanalysis 21 (2009) 2569-2574.

12. R.M. Souto, Y. González-García, J. Izquierdo, S. González, Examination of organic coatings on metallic substrates by scanning electrochemical microscopy in feedback mode: revealing the early stages of coating breakdown in corrosive environments, Corros. Sci. 52 (2010) 748-753.

13. J.J. Santana, J. González-Guzmán, J. Izquierdo, S. González, R.M. Souto, Sensing electrochemical activity in polymer coated metals during the early stages of coating degradation by means of the scanning vibrating electrode technique, Corros. Sci. 52 (2010) 3924-3931.

14. R.M. Souto, Y. González-García, S. González, In Situ monitoring of electroactive species by using the scanning electrochemical microscope. Application to the investigation of degradation processes at defective coated metals, Corros. Sci. 47 (2005) 3312-3323.

15. R.M. Souto, L. Fernández-Mérida, S. González, SECM imaging of interfacial processes in defective organic coatings applied on metallic substrates using oxygen as redox mediator, Electroanalysis 21 (2009) 2640-2646.

16. J.J. Santana, J. González-Guzmán, L. Fernández-Mérida, S. González, R.M. Souto, Visualization of local degradation processes in coated metals by means of scanning electrochemical microscopy in the redox competition mode, Electrochim. Acta 55 (2010) 44884494.

17. A.M. Simoes, D. Battocchi, D.E. Tallman, G.P. Bierwagen, SVET and SECM imaging of cathodic protection of aluminium by a Mg-rich coating, Corros. Sci. 49 (2007) 3838-3849.

18. A. Simões, D. Battocchi, D. Tallman, G. Bierwagen, Assessment of the corrosion protection of aluminium substrates by a Mg-rich primer: EIS, SVET and SECM study, Prog. Org. Coat. 63 (2008) 260-266.

19. E. Salamifar, M.A. Mehrgardi, M.F. Mousavi, Ion transport and degradation studies of a polyaniline-modified electrode using SECM, Electrochim. Acta 54 (2009) 4638-4646.

20. Y. Shao, C. Jia, G. Meng, T. Zhang, F. Wang, The role of a zinc phosphate pigment in the corrosion of scratched epoxy-coated steel, Corros. Sci. 51 (2009) 371-379.

21. Y. Gonzalez-Garcia, J.M.C Mol, T. Muselle, I. De Graeve, G. Van Assche, G. Scheltjens, B. Van Mele, H. Terryn, SECM study of defect repair in self-healing polymer coatings on metals, Electrochem. Commun. 13 (2011) 169-173.

22. M.S. Antelman, The encyclopedia of chemical electrode potentials, Plenum Press, New York, 1982, p. 128. 
23. G. Milazzo, S. Caroli, Tables of standard electrode potentials, John Wiley \& Sons, New York, 1978, p. 229.

24. M.S. Antelman, The encyclopedia of chemical electrode potentials, Plenum Press, New York, 1982, p. 162.
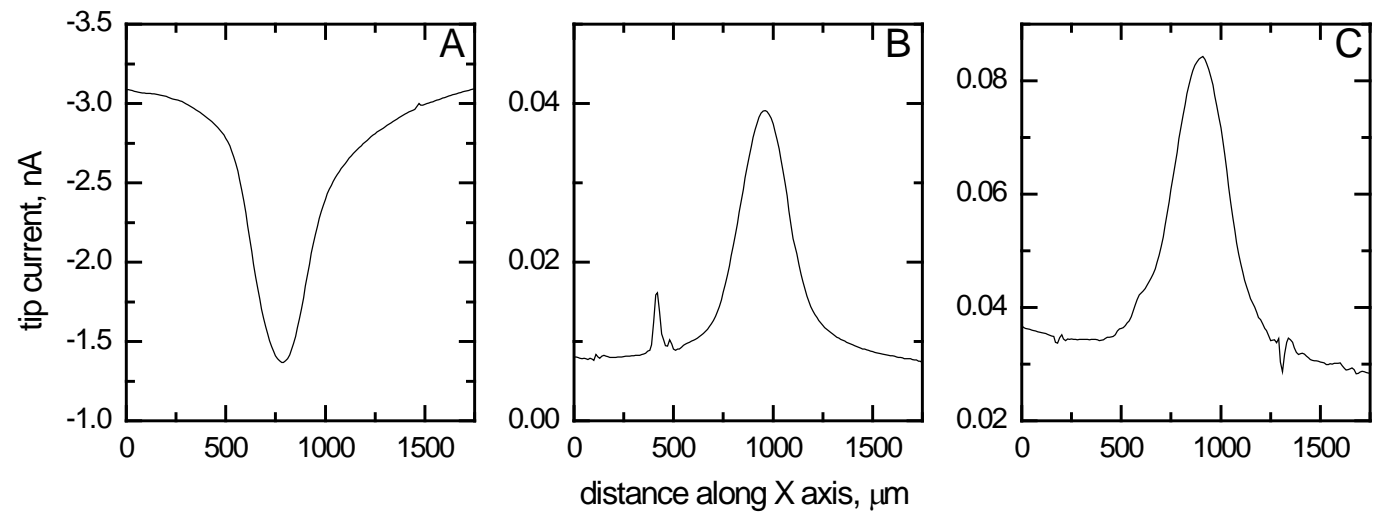

Figure 1 - Line scans of the probe trip across the holiday in the organic coating whereas the sample was polarized (cathodically) at $-1.00 \mathrm{~V}$ vs. $\mathrm{Ag} / \mathrm{AgCl} / \mathrm{KCl}$ (sat.). Test solution: $0.1 \mathrm{M} \mathrm{KCl}$. The tip potentials were: $(A)-0.70,(B)+0.08$, and (C) $+0.60 \vee v s$. $\mathrm{Ag} / \mathrm{AgCl} / \mathrm{KCl}\left(\right.$ sat.). Scan rate: $50 \mu \mathrm{m} \mathrm{s}^{-1}$.

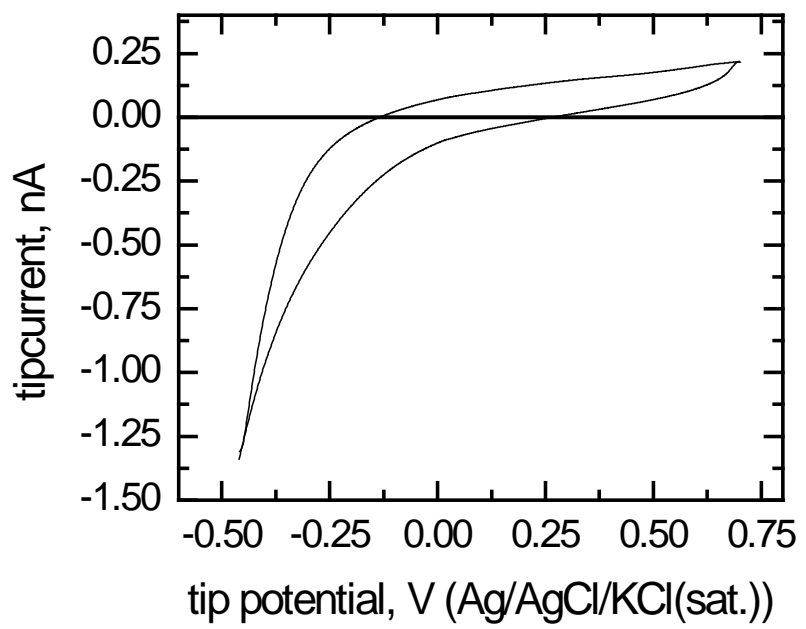

Figure 2 - Cyclic voltammogram measured at the SECM tip in $0.1 \mathrm{M} \mathrm{KCl}$ when placed at the center of the holiday at a height of $10 \mu \mathrm{m}$ in relation to the surrounding intact coating. The coated sample is polarized at $-1.00 \mathrm{~V}$ vs. $\mathrm{Ag} / \mathrm{AgCl} / \mathrm{KCl}$ (sat.). Scan rate: $v=0.05 \mathrm{~V} \mathrm{~s}^{-1}$. It depicts the electrochemical reactions associated with dissolved oxygen in the electrolyte. 

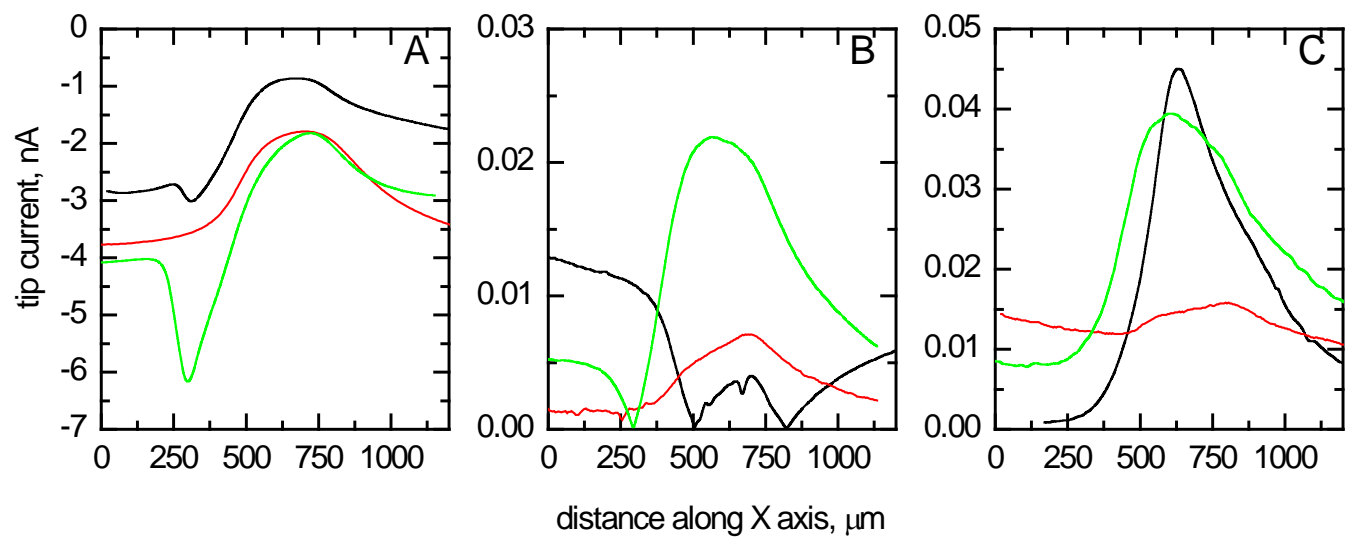

Figure 3 - Line scans of the probe trip across the holiday in the organic coating whereas the sample was polarized (anodically) at $-0.15 \mathrm{~V}$ vs. $\mathrm{Ag} / \mathrm{AgCl} / \mathrm{KCl}$ (sat.). Test solution: $0.1 \mathrm{M} \mathrm{KCl}$. The tip potentials were: $(A)-0.70,(B)+0.25$, and $(C)+0.60 \mathrm{~V} v s$. $A g / A g C l / K C l(s a t$.$) . Scan rate: 30 \mu \mathrm{m} \mathrm{s}^{-1}$.

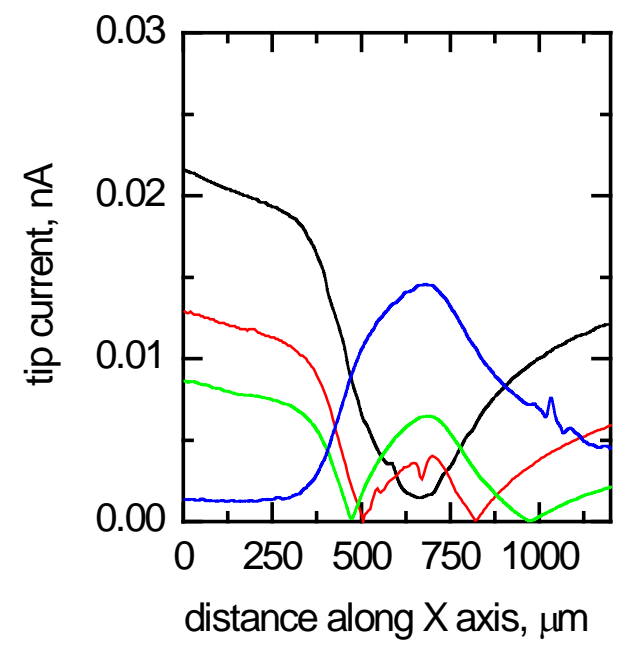

Figure 4 - Line scans of the probe trip across the holiday in the organic coating after the sample was polarized (anodically) at $-0.15 \mathrm{~V}$ vs. $\mathrm{Ag} / \mathrm{AgCl} / \mathrm{KCl}$ (sat.) as given in Figure 3. The sample was first $(-)$ left at its open circuit potential, and subsequently (-•-) polarized (anodically) at -0.15 $\mathrm{V}$ vs. $\mathrm{Ag} / \mathrm{AgCl} / \mathrm{KCl}($ sat.). Test solution: $0.1 \mathrm{M} \mathrm{KCl}$. The tip potentials were: $(\mathrm{A})-0.70,(\mathrm{~B})+0.25$, and (C) $+0.60 \mathrm{~V}$ vs. $\mathrm{Ag} / \mathrm{AgCl} / \mathrm{KCl}\left(\right.$ sat.). Scan rate: $30 \mu \mathrm{m} \mathrm{s}^{-1}$.

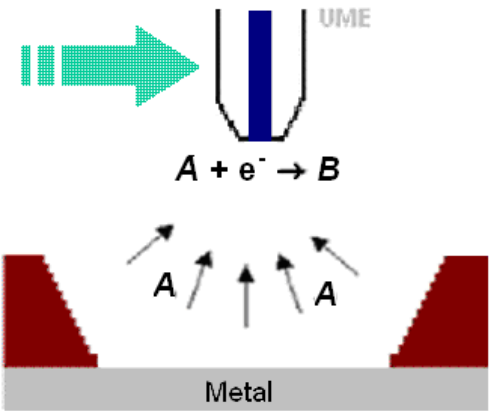

(A)

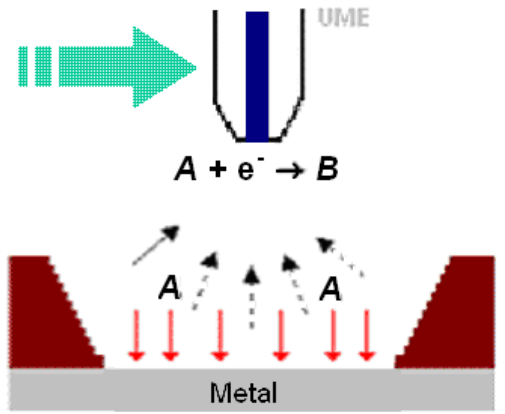

(B)

Figure 5 - Schematics describing the processes occurring at the tip for the electroreduction of species $A$ when it passes above the holiday: $(A)$ in the case that species $A$ is not consumed in a redox reaction on the metal exposed at the bottom of the defect; and (B) when species $A$ is consumed predominantly in a redox reaction on the metal exposed at the bottom of the defect. 